\title{
Beta-amyloid imaging in dementia
}

\author{
Kyung Ah Chun \\ Department of Nuclear Medicine, Yeungnam University College of Medicine, Daegu, Korea
}

\begin{abstract}
Alzheimer's disease (AD) is a neurodegenerative disorder associated with extracellular plaques, composed of amyloid-beta $(A \beta)$, in the brain. Although the precise mechanism underlying the neurotoxicity of $A \beta$ has not been established, $A \beta$ accumulation is the primary event in a cascade of events that lead to neurofibrillary degeneration and dementia. In particular, the $A \beta$ burden, as assessed by neuroimaging, has proved to be an excellent predictive biomarker. Positron emission tomography, using ligands such as ${ }^{11} \mathrm{C}$-labeled Pittsburgh Compound $\mathrm{B}$ or ${ }^{18} \mathrm{~F}$-labeled tracers, such as ${ }^{18} \mathrm{~F}$-florbetaben, ${ }^{18} \mathrm{~F}$-florbetapir, and ${ }^{18} \mathrm{~F}$-flutemetamol, which bind to $A \beta$ deposits in the brain, has been a valuable technique for visualizing and quantifying the deposition of $A \beta$ throughout the brain in living subjects. $A \beta$ imaging has very high sensitivity for detecting $A D$ pathology. In addition, it can predict the progression from mild cognitive impairment to $A D$, and contribute to the development of disease-specific therapies.
\end{abstract}

Keywords: Alzheimer's disease; Amyloid-beta; Positron emission tomography

\section{INTRODUCTION}

With the number of dementia patients rising due to an aging population, it is important to detect dementia early and delay its progression. A variety of diagnostic methods are being used for this purpose, including mental status examination, neurophysiological testing, and magnetic resonance imaging (MRI). Alzheimer's disease (AD) is one of the most common types of dementia, accounting for $70 \%$ of all cases. It is pathologically characterized by deposition of beta-amyloid (A $\beta)$, forming amyloid plaques outside neurons, and an accumulation of hyperphosphorylated tau proteins inside neurons, both of which are known to induce neuronal apoptosis and ultimately cause dementia [1]. Abnormal deposition of $A \beta$ is

Received: October 22, 2017, Revised: November 30, 2017 Accepted: January 3, 2018

Corresponding Author: Kyung Ah Chun, Department of Nuclear Medicine, Yeungnam University College of Medicine, 170, Hyeonchung-ro, Nam-gu, Daegu 42415 Korea

Tel: +82-53-620-3135, Fax: +82-53-620-3135

E-mail: cka52@yumail.ac.kr subsequently followed by synaptic dysfunction, tau protein abnormality in the cerebrospinal fluid (CSF), structural changes of the brain, and cognitive decline (Fig. 1) [2]. Accumulation of $\mathrm{A} \beta$ starts at an early stage of the disease, when no symptoms are present. Studies investigating early biomarkers to differentiate $\mathrm{AD}$ and normal individuals have attempted to predict the progression or onset of $\mathrm{AD}$ from mild cognitive impairment - the intermediate stage between healthy state and dementia - or the preclinical stage - the stage preceding mild cognitive impairment - and halt the progression of the disease [3]. Accumulated $\mathrm{A} \beta$ can be observed in an autopsy or A $\beta 1-42$ can be detected in the CSF; currently, the extent of $\mathrm{A} \beta$ accumulation can be visualized in living patients using neuroimaging. The methods used to visualize $\mathrm{A} \beta$ include positron emission tomography (PET), and new compounds have been developed and approved by the US Food and Drug Administration (FDA) since the development of the C-11 Pittsburgh compound B (PiB) in 2004. Although a fundamental treatment for $\mathrm{AD}$ is still lacking, efforts to develop new therapeutic agents are ongoing, which would serve as useful tests for the diagnosis performed using A $\beta$ PET, and

Copyright $($ C) 2018 Yeungnam University College of Medicine

This is an Open Access article distributed under the terms of the Creative Commons Attribution Non-Commercial License (http://creativecommons.org/licenses/by-nc/4.0/) which permits unrestricted non-commercial use, distribution, and reproduction in any medium, provided the original work is properly cited. 
the assessment of treatment effectiveness [4].

\section{Beta-amyloid}

Found in the brain of patients with $\mathrm{AD}, \mathrm{A} \beta$ is a peptide of 36-43 amino acids, and when it forms plaques, it becomes neurotoxic. This peptide is produced by the action of $\beta$-secretase and $\gamma$-secretase on the amyloid precursor protein [5]. Subsequently, $A \beta$ is converted to amyloid fibrils via a nucleation reaction, after which it accumulates coagulates [6]. Amyloid plaques, which primarily consists of amyloid fibrils, are surrounded by axons, dendrites, reactive astrocytes, and activated microglia (Fig. 2), and A $\beta$ is detected not only in amyloid plaques but also in cortical arteries, CSF, plasma, and neuronal culture [7]. Amyloid plaques can be classified according to density and structure into diffuse plaques, which have a low fibril content, and neuritic plaques, which have a high fibril content [8], with the latter type known to be the more significant indicator of $\mathrm{AD}[9]$.

Although the exact physiological role of $\mathrm{A} \beta$ has not yet been revealed, evidences suggest that it is important for the regulation of synaptic activities and survival of neurons [10]. All available genetic, pathological, biochemical, and cytological evidences support that the gradual accumulation of $\mathrm{A} \beta$ in the brain, as a result of an imbalance of the production and removal of $\mathrm{A} \beta$, is an important factor in the etiology of $\mathrm{AD}$, and despite conflicting arguments, $\mathrm{A} \beta$ is still an important risk factor for $\mathrm{AD}[11,12]$.

\section{Beta-amyloid imaging}

Radiopharmaceuticals for $\mathrm{A} \beta$ imaging have been developed based on the chemical structures of the dyes used to stain $\mathrm{A} \beta$ in the conventional pathologic examination. These substances

Clinical Symptoms

\section{Functional Impairment}

Cognitive Impairment

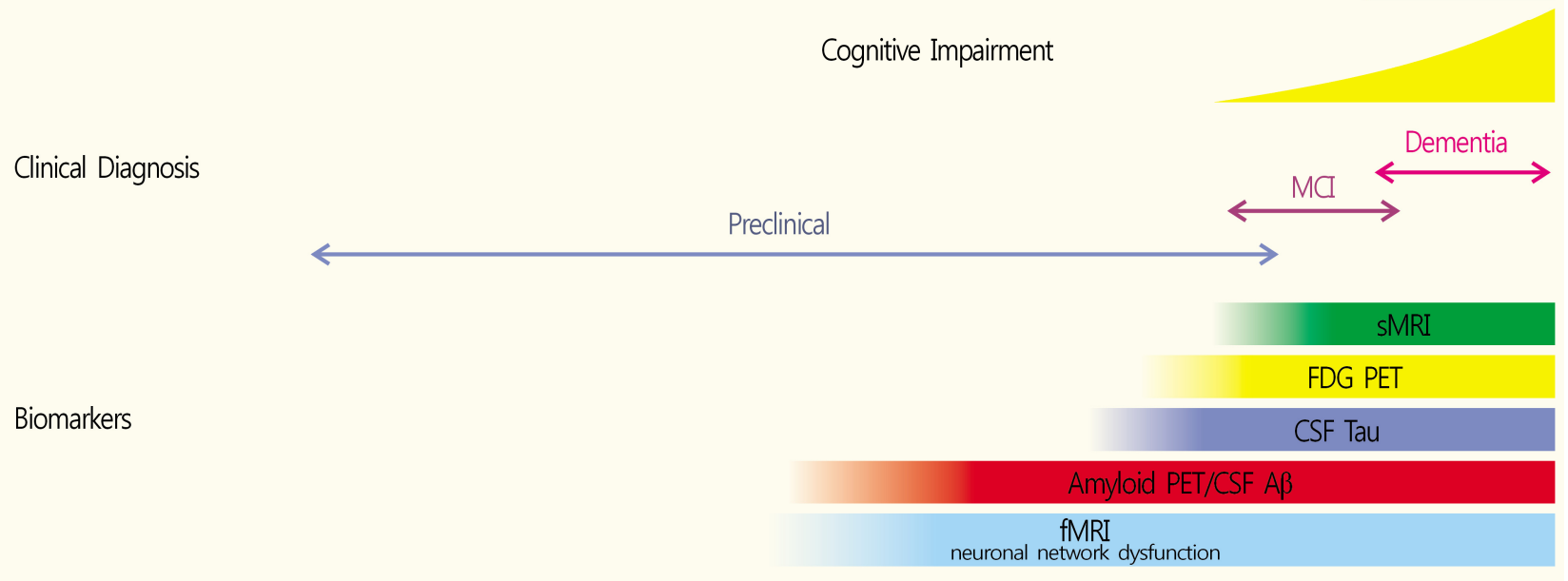

Pathological Changes

Tau

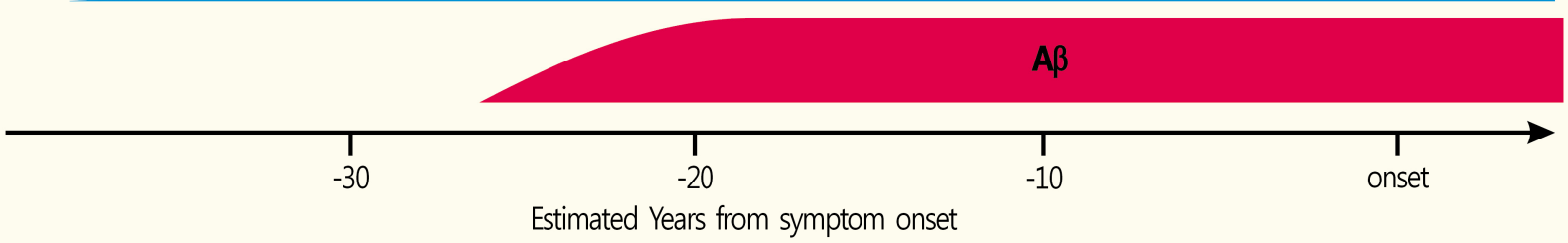

Fig. 1. Chronological relationships among pathology, clinical symptoms and biomarkers. Based on biomarker studies, $\beta$-amyloid protein accumulation appears to start-20 years before the onset of dementia (adapted from Yoshiyama et al. J Neurol Neurosurg Psychiatry 2013;84:784-95, with permission of British Medical Association). MCI, mild cognitive impairment; sMRI, structural MRI; FDG, $2-\left[{ }^{18} \mathrm{~F}\right]$-fluoro-2-deoxy-D-glucose; PET, positron emission tomography; CSF, cerebrospinal fluid; $\mathrm{A} \beta, \beta$-amyloid protein; fMRI, functional magnetic resonance imaging. 
were modified by eliminating their ionization properties, and enhancing their lipophilic properties, such that they could penetrate the blood brain barrier, and accumulate in the parts of the brain containing $\mathrm{A} \beta$ aggregates [13]. Most $\mathrm{A} \beta$ imaging methods involve the use of a PET tracer known as ${ }^{11} \mathrm{C}-\mathrm{PiB}$, but its use is limited due to its short half-life (20 min). Recently, a fluoride $\left({ }^{18} \mathrm{~F}\right)$ marker with a long half-life (110 min) has been used in several ongoing clinical trials; of them, Amyvid (florbetapir; ${ }^{18} \mathrm{~F}-\mathrm{AV}-45$ ) was the first to be approved by the FDA in 2012, followed by Vizamyl (flutemetamol; GE-067) in 2013, and Neuraceq (florbetaben; BAY 94-9172) in 2014. Currently, Neuraceq and Vizamyl are being used in South Korea. Owing to its high sensitivity, $\mathrm{A} \beta$ imaging enables early diagnosis, and can predict the progression of mild cognitive impairment to $\mathrm{AD}$. In particular, a two-year follow-up study of patients with mild cognitive impairment reported that those who progressed to $\mathrm{AD}$ had a higher uptake of ${ }^{11} \mathrm{C}-\mathrm{PiB}$ than those who did not convert to $A D$, suggesting that $A \beta$ PET is useful for the early diagnosis of $\mathrm{AD}$ [13]. In a study that examined the local deposition of $\mathrm{A} \beta$ radiological tracers, and the presence of local amyloid plaques reported in autopsies or biopsies of patients with $\mathrm{AD}$, the agreement rate between the two exceeded $96 \%[14,15]$. The deposition of $A \beta$ is usually observed in the cerebral cortex of patients with $\mathrm{AD}$, that is, it is deposited in the gray matter, including the prefrontal, medial parietal, lateral temporal, and cingulate gyrus and subcortical striatum (Fig. 3) [16,17]. Images are analyzed and determined as positive or negative by comparing the radioactivity between the grey matter in the cerebral cortex and the proximal white matter. When negative, the contrast between

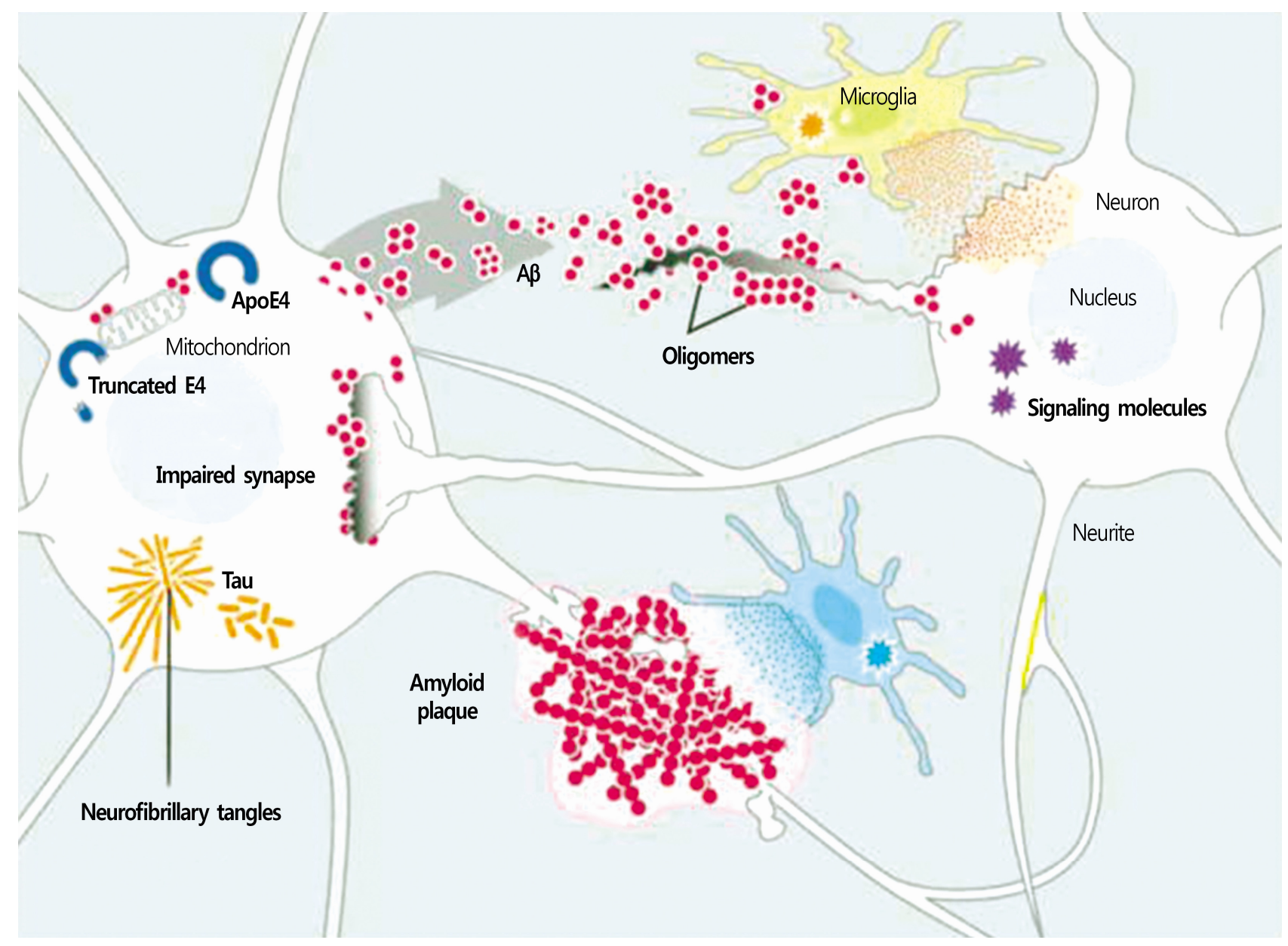

Fig. 2. Molecular and cellular processes presumed to participate in $\mathrm{AD}$ pathogenesis. $\mathrm{A} \beta$ peptides produced by neurons and other brain cells and build-up of pathogenic $\mathrm{A} \beta$ assemblies could result from increased production or aggregation or from deficient clearance mechanisms (adapted from Roberson et al. Science 2006;314:781-4, with permission of American Association for the Advancement of Science). $\mathrm{AD}$, Alzheimer's disease; $\mathrm{A} \beta, \beta$-amyloid protein. 
the white and grey matters is clear, showing elevated radioactivity in the white matter as opposed to the grey matter; however, when positive, the contrast between the two is weakened, and it is difficult to distinguish the white matter from the grey matter. Therefore, $\mathrm{A} \beta$ PET images can provide additional information to confirm the diagnosis in cases where the diagnosis of $\mathrm{AD}$ is uncertain, and are also highly useful for distinguishing between frontotemporal dementia and $\mathrm{AD}$ [18]. However, such $\mathrm{A} \beta$ images are not specific to $\mathrm{AD}$, as they are positive also for dementia with Lewy bodies and cerebral amyloid angiopathy, hindering differential diagnosis [19]. Therefore, $A \beta$ images should be accepted as a general marker of cerebral amyloidosis, not a specific marker for amyloidosis in the patients with $\mathrm{AD}$.

Moreover, $\mathrm{A} \beta$ images can be meaningful even when observed in dementia other than $\mathrm{AD}$. In dementia with Lewy body, high $\mathrm{A} \beta$ deposition is associated with a more severe cognitive impairment, and a better response to choline esterase inhibitors, while $\mathrm{A} \beta$ deposition in Parkinson's disease signifies rapid progression to dementia [20-22]. These findings suggest that $\alpha$ synucleinopathy can coexist with the pathology of $\mathrm{AD}$ [23].
However, one shortcoming is that the possibility of testing positive for $A \beta$ increases with age, and amyloid plaques can be observed on A $\beta$ PET even in elderly individuals with normal cognitive function. In fact, positive findings can be observed in under 5, 10, 25, and 50\% of the people in their 50s60s, 60s-70s, 70s-80s, and 80s-90s, respectively [24,25]. Even in patients without dementia, the prevalence of cerebral $\mathrm{A} \beta$ pathology, determined based on A $\beta$ PET or CSF findings, is associated with age, and the formation of amyloid plaques in patients with dementia can begin up to 20 years prior to the onset of clinical symptoms [26,27]. Thus, indications for A $\beta$ PET application have been suggested as follows: first, patients with persistent or progressive mild cognitive impairment with an unknown cause; second, patients with a possibility of $\mathrm{AD}$, with unclear clinical symptoms, and third, relatively younger patients (aged 65 years or less) with progressive dementia. It is generally not performed for determining the severity of symptoms [28].

In addition to $\mathrm{A} \beta \mathrm{PET}$, computed tomography or brain MRI are also used to measure brain volume, shape, and intensity to assess the loss or atrophy of brain tissue to identify the
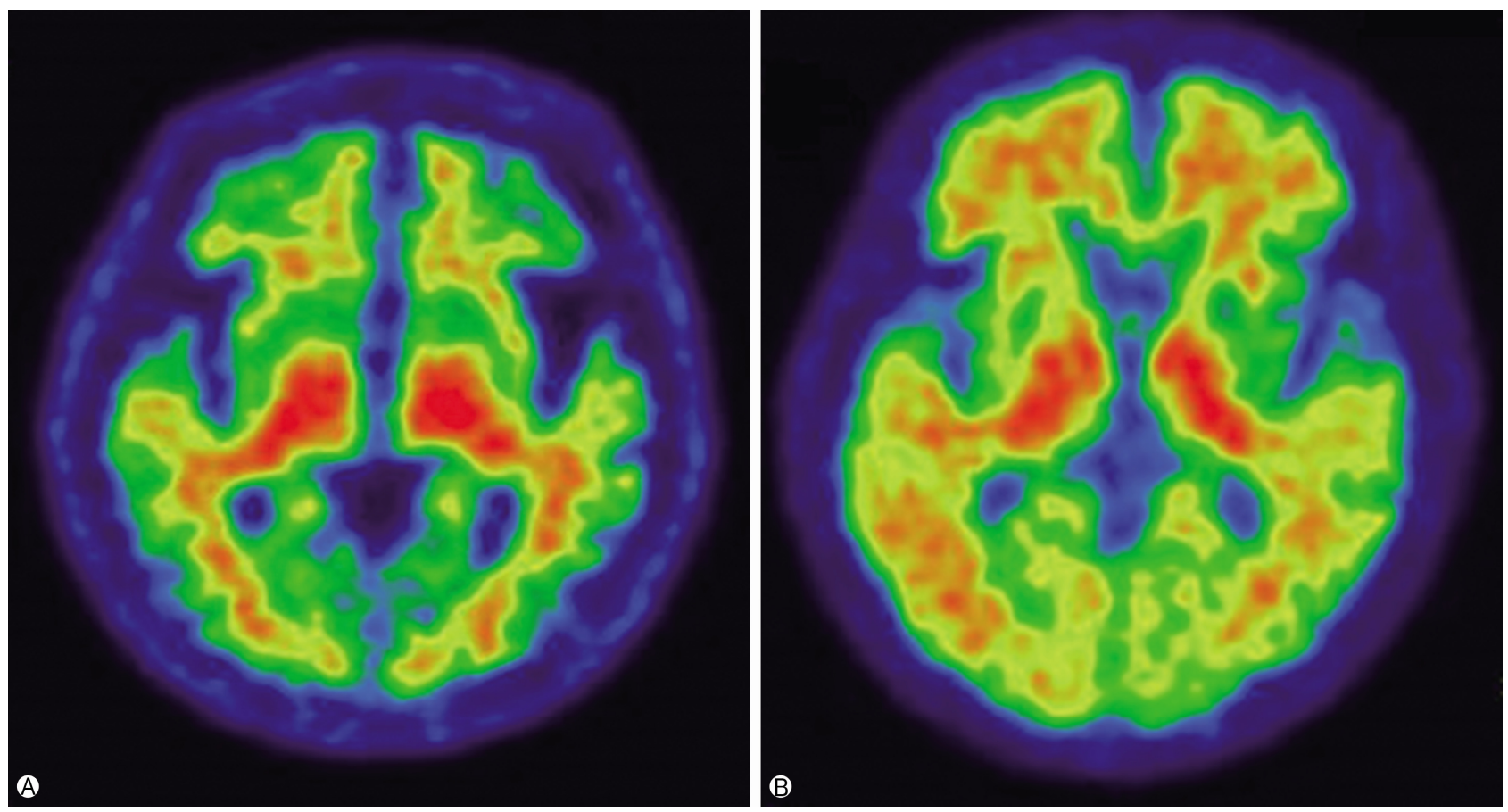

Fig. 3. Axial view of ${ }^{18} \mathrm{~F}$-flutemetamol positron emission tomography scans. Negative image (A) shows a white matter sulcal pattern at the frontal and lateral temporal regions with a color intensity that tapers to the periphery, as well as less radioactivity in the striatal region(s). Positive image (B) shows absence of the white matter sulcal pattern with intensity radiating to a sharply defined convex edge, as well as more radioactivity in the striatum. 
pathophysiology of $\mathrm{AD}$. Many studies have reported that atrophy of the medial temporal area is observed from an early stage of $\mathrm{AD}$, and a meta-analysis of a brain volume study has reported a sensitivity of $78-94 \%$ and specificity of $60-100 \%$ for differentiating $\mathrm{AD}$ from normal condition $[3,29]$. In addition, changes in brain activities can be measured by regional blood flow or measuring glucose metabolism using fluorodeoxyglucose (FDG) PET. Studies using FDG-PET have found that metabolism is reduced in the medial temporal area, parietal area, and posterior cingulate gyrus. Reduced metabolism is also observed in the frontal lobe in more advance stages of $\mathrm{AD}$. These patterns are in contrast with the preservation of the primary motor/visual cortex, cerebellum, thalamus, and basal ganglia [3,30]. An A $\beta$ PET study using PiB differentiated between frontotemporal dementia and $\mathrm{AD}$ with an accuracy of 97\% [18], while it differentiated between $\mathrm{AD}$ and other neurodegenerative diseases with an accuracy of $87.5 \%$ $[31,32]$. Interestingly, A $\beta$ PET yields negative results for frontotemporal dementia, which helps in the differentiation of $\mathrm{AD}$, and development of treatment plans. A recent study investigating the usefulness of $A \beta$ images suggested that they lead to a change in diagnosis for about $30 \%$ of the patients, and a change in treatment policies for about $60 \%$ of the patients [33].

Although there is no cure for $\mathrm{AD}$, symptomatic treatment using acetylcholinesterase inhibitors or glutamatergic modulators can bring about temporary stabilization, though not a marked improvement in memory [34]. Other treatment methods are currently being developed, one of which is antibody-based immunotherapy, which targets $\mathrm{A} \beta$ to inhibit the accumulation of or remove $A \beta$ in the brain, delaying the progression of the disease. In a phase two clinical trial for bapineuzumab (a humanized anti-amyloid-beta monoclonal antibody), A $\beta$ PET images and tau protein concentrations in the CSF differed according to the presence of apolipoprotein $\mathrm{E}$ $\varepsilon 4$, but the agent did not improve cognitive functions or other symptoms in patients with $\mathrm{AD}$ [35]. A recent study of aducanumab found that treatment led to reduction of amyloid plaques in $\mathrm{A} \beta$ PET images, and that the agent delayed the deterioration of cognition [36]. Therefore, A $\beta$ PET imaging is expected to be useful in monitoring the progression of a disease or treatment effects by accurate diagnosis of $\mathrm{AD}$ in the early or preclinical stages, and measuring the $\mathrm{A} \beta$ accumulation in the brain [13].

\section{CONCLUSION}

The number of patients with dementia is rising due to an aging population, and most of these patients are diagnosed with $\mathrm{AD}$. The disease is pathologically characterized by amyloid plaques outside neurons and accumulation of tau protein within neurons, which are known to induce $\mathrm{AD}$ by promoting neuronal apoptosis [1]. Detecting accumulated $\mathrm{A} \beta$ before the onset of symptoms is highly important, as individuals in this stage can potentially benefit from treatments that aim to reduce or remove $A \beta$ in the brain before an irreversible loss of neurons or synapses occurs [37]. In this context, the importance of early diagnostic methods using imaging biomarkers has been emphasized, and PET scans that visualize A $\beta$ are expected to play an important role in the early diagnosis of $\mathrm{AD}$ and the development of therapeutic agents [23].

\section{CONFLICT OF INTEREST}

No potential conflict of interest relevant to this article was reported.

\section{ORCID}

Kyung Ah Chun, https://orcid.org/0000-0002-2296-4340

\section{REFERENCES}

1. Querfurth HW, LaFerla FM. Alzheimer's disease. N Engl J Med 2010;362:329-44.

2. Yoshiyama Y, Lee VM, Trojanowski JQ. Therapeutic strategies for tau mediated neurodegeneration. J Neurol Neurosurg Psychiatry 2013;84:784-95.

3. Won WY, Lee CU. Biomarkers for Alzheimer's dementia: focus on neuroimaging. Korean J Biol Psychiatry 2011;18:7279. Korean.

4. Villemagne VL, Doré V, Bourgeat P, Burnham SC, Laws S, Salvado $\mathrm{O}$, et al. $\mathrm{A} \beta$-amyloid and tau imaging in dementia. Semin Nucl Med 2017;47:75-88.

5. Murphy MP, LeVine H 3rd. Alzheimer's disease and the amyloid-beta peptide. J Alzheimers Dis 2010;19:311-23.

6. Harper JD, Lansbury PT Jr. Models of amyloid seeding in Alzheimer's disease and scrapie: mechanistic truths and physiological consequences of the time-dependent solubility of amyloid proteins. Annu Rev Biochem 1997;66:385-407. 
7. Seubert P, Vigo-Pelfrey C, Esch F, Lee M, Dovey H, Davis D, et al. Isolation and quantification of soluble Alzheimer's beta-peptide from biological fluids. Nature 1992;359:325-7.

8. Dickson TC, Vickers JC. The morphological phenotype of beta-amyloid plaques and associated neuritic changes in Alzheimer's disease. Neuroscience 2001;105:99-107.

9. Knopman DS, Parisi JE, Salviati A, Floriach-Robert M, Boeve BF, Ivnik RJ, et al. Neuropathology of cognitively normal elderly. J Neuropathol Exp Neurol 2003;62:1087-95.

10. Pearson HA, Peers C. Physiological roles for amyloid beta peptides. J Physiol 2006;575:5-10.

11. Villemagne VL, Cappai R, Barnham KJ, Cherny RA, Opazo C, Novakovic KE, et al. The A $\beta$ centric pathway of Alzheimer's disease. In: Barrow CJ, Small DH, editors. Abeta peptide and Alzheimer's disease: celebrating a century of research. London: Springer; 2007. p. 5-32.

12. Hardy J. Amyloid, the presenilins and Alzheimer's disease. Trends Neurosci 1997;20:154-9.

13. Kim JS, Oh SJ, Moon DH. Molecular imaging in neurodegenerative diseases. J Korean Med Assoc 2009;52:151-67. Korean.

14. Clark CM, Schneider JA, Bedell BJ, Beach TG, Bilker WB, Mintun MA, et al. Use of florbetapir-PET for imaging betaamyloid pathology. JAMA 2011;305:275-83.

15. Wolk DA, Grachev ID, Buckley C, Kazi H, Grady MS, Trojanowski JQ, et al. Association between in vivo fluorine 18-labeled flutemetamol amyloid positron emission tomography imaging and in vivo cerebral cortical histopathology. Arch Neurol 2011;68:1398-403.

16. Klunk WE, Engler H, Nordberg A, Wang Y, Blomqvist G, Holt DP, et al. Imaging brain amyloid in Alzheimer's disease with Pittsburgh Compound-B. Ann Neurol 2004;55:306-19.

17. Kemppainen NM, Aalto S, Wilson IA, Nagren K, Helin S, Brück A, et al. Voxel-based analysis of PET amyloid ligand [11C]PIB uptake in Alzheimer disease. Neurology 2006;67: 1575-80.

18. Rabinovici GD, Rosen HJ, Alkalay A, Kornak J, Furst AJ, Agarwal N, et al. Amyloid vs FDG-PET in the differential diagnosis of AD and FTLD. Neurology 2011;77:2034-42.

19. Lehmann M, Ghosh PM, Madison C, Laforce R Jr, CorbettaRastelli C, Weiner MW, et al. Diverging patterns of amyloid deposition and hypometabolism in clinical variants of probable Alzheimer's disease. Brain 2013;136:844-58.

20. Gomperts SN, Locascio JJ, Marquie M, Santarlasci AL, Rentz DM, Maye J, et al. Brain amyloid and cognition in Lewy body diseases. Mov Disord 2012;27:965-73.

21. Graff-Radford J, Boeve BF, Pedraza O, Ferman TJ, Przybelski $\mathrm{S}$, Lesnick TG, et al. Imaging and acetylcholinesterase inhibitor response in dementia with Lewy bodies. Brain 2012; 135:2470-7.

22. Gomperts SN, Locascio JJ, Rentz D, Santarlasci A, Marquie $\mathrm{M}$, Johnson KA, et al. Amyloid is linked to cognitive decline in patients with Parkinson disease without dementia. Neurology 2013;80:85-91.

23. Xia C, Dickerson BC. Multimodal PET imaging of amyloid and tau pathology in Alzheimer disease and non-Alzheimer disease dementias. PET Clin 2017;12:351-9.

24. Rowe CC, Ellis KA, Rimajova M, Bourgeat P, Pike KE, Jones $\mathrm{G}$, et al. Amyloid imaging results from the Australian Imaging, Biomarkers and Lifestyle (AIBL) study of aging. Neurobiol Aging 2010;31:1275-83.

25. Wang F, Gordon BA, Ryman DC, Ma S, Xiong C, Hassenstab $\mathrm{J}$, et al. Cerebral amyloidosis associated with cognitive decline in autosomal dominant Alzheimer disease. Neurology 2015; 85:790-8.

26. Jansen WJ, Ossenkoppele R, Knol DL, Tijms BM, Scheltens $\mathrm{P}$, Verhey FR, et al. Prevalence of cerebral amyloid pathology in persons without dementia: a meta-analysis. JAMA 2015; 313:1924-38.

27. Jack CR Jr, Lowe VJ, Weigand SD, Wiste HJ, Senjem ML, Knopman DS, et al. Serial PIB and MRI in normal, mild cognitive impairment and Alzheimer's disease: implications for sequence of pathological events in Alzheimer's disease. Brain 2009; 132:1355-65.

28. Johnson KA, Minoshima S, Bohnen NI, Donohoe KJ, Foster NL, Herscovitch P, et al. Update on appropriate use criteria for amyloid PET imaging: dementia experts, mild cognitive impairment, and education. Amyloid Imaging Task Force of the Alzheimer's Association and Society for Nuclear Medicine and Molecular Imaging. Alzheimers Dement 2013;9:e106-9.

29. Bosscher L, Scheltens P. MRI of the medial temporal lobe for the diagnosis of Alzheimer's disease. In: Qizilbash N, editor. Evidence-based dementia practice. Osney Mead, Oxford; Malden, MA: Blackwell Science; 2002. p. 154-62.

30. Mosconi L, Tsui WH, Herholz K, Pupi A, Drzezga A, Lucignani $\mathrm{G}$, et al. Multicenter standardized 18F-FDG PET diagnosis of mild cognitive impairment, Alzheimer's disease, and other dementias. J Nucl Med 2008;49:390-8.

31. Arbizu J, García-Ribas G, Carrió I, Garrastachu P, MartínezLage P, Molinuevo JL. Recommendations for the use of PET imaging biomarkers in the diagnosis of neurodegenerative conditions associated with dementia: SEMNIM and SEN consensus. Rev Esp Med Nucl Imagen Mol 2015;34:303-13.

32. Sánchez-Juan P, Ghosh PM, Hagen J, Gesierich B, Henry M, Grinberg LT, et al. Practical utility of amyloid and FDG-PET in an academic dementia center. Neurology 2014;82:230-8.

33. Barthel H, Sabri O. Clinical use and utility of amyloid imaging. J Nucl Med 2017;58:1711-7.

34. Masters CL, Beyreuther K. Alzheimer's centennial legacy: prospects for rational therapeutic intervention targeting the Abeta amyloid pathway. Brain 2006;129:2823-39.

35. Salloway S, Sperling R, Fox NC, Blennow K, Klunk W, Raskind $\mathrm{M}$, et al. Two phase 3 trials of bapineuzumab in mild-tomoderate Alzheimer's disease. N Engl J Med 2014;370:32233.

36. Sevigny J, Chiao P, Bussière T, Weinreb PH, Williams L, Maier $\mathrm{M}$, et al. The antibody aducanumab reduces $\mathrm{A} \beta$ plaques in Alzheimer's disease. Nature 2016;537:50-6.

37. Sperling RA, Jack CR Jr, Aisen PS. Testing the right target and right drug at the right stage. Sci Transl Med 2011;3:11133. 